\title{
Accuracy and diagnostic value of diffusion- weighted whole body imaging with background body signal suppression (DWIBS) in metastatic breast cancer
}

\author{
Mohamed Gaber Eissawy ${ }^{1}$, Amr M. Ismaeel Saadawy ${ }^{2}$, Kamel Farag ${ }^{3}$, Tamer Akl ${ }^{3}$ and Wael Hamza Kamr T, $^{*}$
}

\begin{abstract}
Background: Breast cancer is the most common malignant tumor among women. The mortality of the patients could be mainly attributed to metastasis and spread of breast cancer to distant sites. The objective of the current study is to evaluate and express the role of diffusion-weighted whole body imaging with background body signal suppression (DWIBS) in detection of osseous and soft tissue metastatic lesions in patients with cancer breast.

Results: The current prospective study included 50 female patients with pathologically proven breast cancer. The overall sensitivity of DWIBS and STIR were $97.5 \%$ and $92.5 \%$, respectively. DWIBS was the most sensitive sequence with highest negative predictive values. DWIBS and STIR were the most sensitive with the highest negative predictive value. Both DWIBS and STIR detected more vertebral metastatic deposits (100\% and $97.8 \%$, respectively) and more soft tissue lesions (94.4\% for both) than WB DWI and T1WI.
\end{abstract}

Conclusion: DWIBS MRI sequence is an effective method for detection of solid organ, bone and lymph node metastasis but not specific for characterization of lesions.

Keywords: Breast cancer, WB-DWI, DWIBS, Metastasis

\section{Background}

Breast cancer is the most common malignant tumor among women. Its incidence is increasing with progress of age and its peak is seen among 50-60 age groups. The mortality of the patients could be mainly attributed to metastasis and spread of breast cancer to distant sites beyond axillary lymph nodes [1]. Breast cancer can spread to anywhere in body, involving the lungs, liver, or brain in addition to the regional lymph nodes. However, bony metastasis is the most common. Once a malignant tumor is detected, determination of its extension is

\footnotetext{
* Correspondence: dr.waelkamr@gmail.com

${ }^{4}$ Radiology Department, Mansoura University, El Gomhorya St, Mansoura 35111, Egypt

${ }^{5}$ Faculty of Medicine, Department of Diagnostic and Intervention Radiology, Mansoura University, El Gomhorya St, Mansoura 35111, Egypt

Full list of author information is available at the end of the article
}

important for appropriate treatment planning including surgery, radiation, chemotherapy, biological, and/or hormonal therapy [2].

Management decision of oncology patient is based on the presence of metastatic lesion, either bony or soft tissue, in addition to the size and extension of the lesions. This information can be obtained by Bone scans or PET-CT scans, however whole body MR imaging can provide the same information $[3,4]$. Considering the condition of the oncology patients, they are already weakened, not only by the disease entity itself, but also by chemotherapy, so over radiation exposure as in bone scans or PET-CT scans may worsen the condition of the patients $[5,6]$. It was reported that MRI can detect bone metastasis even before they manifest on the bone scan, plus they are non-invasive and radiation free $[7,8]$.

\section{Springer Open}

๑ The Author(s). 2021 Open Access This article is licensed under a Creative Commons Attribution 4.0 International License, which permits use, sharing, adaptation, distribution and reproduction in any medium or format, as long as you give appropriate credit to the original author(s) and the source, provide a link to the Creative Commons licence, and indicate if changes were made. The images or other third party material in this article are included in the article's Creative Commons licence, unless indicated otherwise in a credit line to the material. If material is not included in the article's Creative Commons licence and your intended use is not permitted by statutory regulation or exceeds the permitted use, you will need to obtain permission directly from the copyright holder. To view a copy of this licence, visit http://creativecommons.org/licenses/by/4.0/. 
Diffusion-weighted image (DWI) of the entire body is a promising technique, that can provide important information about the movement and functional status of the microenvironment of water in tissue. Changes in diffusion of water within pathological tissue may occur before they are seen on standard MR imaging $[9,10]$. The concept of diffusion-weighted whole body imaging with background body signal suppression (DWIBS) allows unique features that may play an important role in whole body oncological imagining $[8,11]$.

This advanced technology allows quick performance of DWI in assessment of oncology patients with the application of whole body DWI, using the DWIBS [12, 13]. This application is available in almost all of the MRI machines, easily performed, takes short time and does not need contrast injection [14, 15]. In addition, MRI machines are widely available and less expensive than PETCT or SPECT/CT with no radiation hazards which is the most important point $[16,17]$. Whole body DWI technique can be applied as a routine method in metastatic workup of oncology patients instead of bone scan and PET-CT. It can help the clinicians to take their management decisions easily and more confident $[3,18]$.

The aim of this study is to evaluate and express the role of diffusion-weighted whole body imaging with background body signal suppression (DWIBS) in detection of osseous and soft tissue metastatic lesions in patients with cancer breast.

\section{Methods}

Fifty female patients were included in this study, referred during the period from September 2017 to March 2019, their ages ranged from 31 to 76 years. All the patients were pathologically proved to have breast cancer.

Each patient was subject to the following:

History taking in details.

Through clinical evaluation.

Reviewing laboratory investigations and pathological reports.

Reviewing previously done radiological investigations

(MDCT, ultrasonography, bone scan)

\section{MRI examination}

All scans were performed on a 1.5 Tesla Achieva MRI machine (gradient strength $=33 \mathrm{mT} / \mathrm{m}$, slew rate $=122$ $\mathrm{T} / \mathrm{m} / \mathrm{s}$, Philips Medical system). All the 50 patients underwent T1 WI, STIR, DWIBs, and WB-DWI with multiple $b$ values.

The detected metastatic lesions of the 50 patients by modalities as computed tomography and bone scan were classified into bony and soft tissue metastatic lesions. These findings will be compared to the findings of whole body MRI sequences.

\section{Inclusion criteria}

Patients with known cancer breast and suspected osseous, nodal, or solid organ metastases.

\section{Exclusion criteria}

Patients with MRI contraindication like heart pacemaker, metallic foreign body, metallic stent, or aneurysm clips.

Claustrophobic patients

\section{Patient preparation}

No special preparation was needed.

Any metallic object was removed before performing MRI

No need for contrast administration.

\section{MRI imaging protocol DWIBS parameters}

We use the SENSE parallel imaging technique in axial image with 4 stacks using the body coil that reconstructed in coronal view in following parameters (Table 1).

\section{WB-DWI parameters}

Axial DWI from the skull vault to the mid-thigh is performed using $b$ values of $50 \mathrm{~s} / \mathrm{mm}^{2}$ and a $b$ value of 900 $\mathrm{s} / \mathrm{mm}^{2}$ with a slice thickness of $5 \mathrm{~mm}$. The axial DWI acquisition is usually achieved in 4 contiguous stations with each station taking approximately $6 \mathrm{~min}$ to acquire. The high $b$ value images are then reconstructed in orthogonal planes as thin multiplanar reconstructions (5 $\mathrm{mm}$ ) and as thick 3D maximum intensity projections (MIPs) which are usually displayed using an inverted grey scale. ADC maps are computed in line with system soft-ware using mono exponential fitting in which each voxel reflects the tissue diffusivity (unit: $\mu \mathrm{m}^{2} / \mathrm{s}$ )

T1WI and STIR whole body MRI images were also done in coronal planes for each patient with free breathing technique and the following parameters (Table 2).

Table 1 The resulting DWIBS images were displayed by using black and white inverse gray scales

\begin{tabular}{ll}
\hline Parameters & Value \\
\hline TR & $>5000 \mathrm{~ms}$ \\
TE & $<70 \mathrm{~ms}$ \\
EPI factors & 47 \\
SENSE factor & 2 \\
$b$ value & $1000 \mathrm{~s} / \mathrm{mm}$ \\
Slice thickness & $4 \mathrm{~mm}$ \\
Breath hold & Not needed \\
Total acquisition time & $10 \mathrm{~min}$ \\
\hline
\end{tabular}


Table 2 Whole body MRI also included TI and STIR pulse sequences parameters

\begin{tabular}{llll}
\hline Parameters & T1 & T2 & STIR \\
\hline TR & 466 & 1221 & 6800 \\
TE & 18 & 80 & 70 \\
FOV: & & & \\
$\quad$ Right/left & 530 & 530 & 530 \\
$\quad$ Anterior/posterior & 265 & 275 & 277 \\
$\quad$ Feet/head & 224 & 224 & 224 \\
Slice thickness & $8 \mathrm{~mm}$ & $8 \mathrm{~mm}$ & $8 \mathrm{~mm}$ \\
Gap & $1 \mathrm{~mm}$ & $1 \mathrm{~mm}$ & $1 \mathrm{~mm}$ \\
\hline
\end{tabular}

\section{Image assessment}

The MRI findings were assessed independently by two well experienced radiologists (10 and 8 years post MD). They had access only to the clinical history. Conjoint meeting was done if there was any controversy and reviewing the case to reach final decision.

DWIBS images were applied in inverted grey scale and applied in 2D MIP coronal images, while WB-DWI was applied in both, coronal and axial cuts which consumes much more time for interpretation. Anatomical correlation was done by $\mathrm{T} 1$ and STIR sequences.

The criteria for the solid organ (lung, liver, spleen, pancreas, kidney, suprarenal, bowel loops) and bone marrow focal lesions were abnormal signal intensity displaying low signal intensity on T1WI and high signal intensity on STIR, WB-DWI, and DWIBS.

The criteria for pathological lymph node involvement were the same signal abnormality as the previously described lesions in addition to the size (positive when more than $1 \mathrm{~cm}$ ) or forming mass lesion.

The number and localization of the lesions were compared among the different sequences to find which one can detect more lesions.

In DWIBS, qualitative analysis can be performed directly from the reformatted view on the three planes. The normal appearance of different organs varies from each other. The normal blood vessels, fat, muscle, and bowel show suppressed signals while other normal structures like the spleen, ovaries, endometrium, and the spinal cord remain visible. Subjective classification of the lesions was done based on the signal pattern and intensity in addition to its shape. The ADC value is not applicable in DWIBS. Generally, malignant lesions show high SI and variable appearance than the benign lesions. Beside diffusion-weighted sequence, information obtained from T1-weighted and STIR images for accurate pathological detection and to exclude artifacts from the diffusionweighted sequence images.

All results were correlated with findings detected by other imaging modalities if available, like contrast- enhanced CT for soft tissue lesion and bone scan for bone metastases (Table 3).

\section{Statistical analysis}

The data collected was analyzed and findings were obtained using the statistical package for social science (SPSS) windows package version 22.0. Descriptive analysis was conducted, i.e., frequencies and percentages for the continuous variables such as age and for categorical variables such as gender, mean, and standard deviation. Sensitivity, specificity, negative, and positive predictive values were calculated by using $\mathrm{CT}$ and bone scan findings as a standard of reference.

\section{Results}

Fifty breast cancer female patients were included in the study; age ranged from 31 to 76 years (mean $49.16 \pm$ 14.041). All patients were pathologically proven to be invasive duct carcinoma. All patients were subjected to MRI examination in the form of whole body T1WI, STIR, DWIBS, and whole body diffusion with multiple $b$ values. In all patients, the distant metastases were well depicted in lymph nodes, solid organs, and bone marrow in T1WI, STIR images, and DWIBS and WB-DW.

All the images were technically appropriate, and no technique-related complications were observed. All the images presented a good quality, despite the presence of artifacts, not affecting the diagnostic outcome. Such artifacts occurred pre-dominantly in the chest and abdomen, and were caused by breathing, heartbeats and/or body motion.

In all patients, the distant metastases were well depicted in soft tissue (liver, lung, brain, breast and lymph nodes) and bone marrow in all sequences; T1WI, STIR,WB-DWI, and DWIBS.

On calculating time taking for each sequence, it was obviously noted that DWIBS takes the least time which was easier for the patients. Whole body T1 and STIR MRI sequences take about $30 \mathrm{~min}$ each. Whole body DWI MRI with two $b$ values takes about $45 \mathrm{~min}$, and DWIBS takes only $10-15 \mathrm{~min}$.

There was a good agreement between the two radiologists regarding the MRI findings and interpretation with

Table 3 Results of $C T$ and bone scan in 50 patients as gold standard

\begin{tabular}{ll}
\hline CECT and bone scan findings & Number \\
\hline Bony lesions & 20 cases \\
Soft tissue lesions & 10 cases \\
Both bone \& soft tissue lesions & 10 cases \\
No lesions & 10 cases \\
Soft tissue lesions detected by CECT & 36 lesions \\
Bony lesion detected by bone scan & 45 lesions \\
\hline
\end{tabular}


a minor controversy solved by conjoint meeting and reviewing the case together to take final decision

The detected lesions were categorized into two main types: bony and soft tissue lesions, and then subcategorized according to their anatomical sites. The total lesions are calculated in all cases and the sensitivity, specificity, positive, and negative predictive values are calculated for each in comparison to the findings of the previously done CECT and bone scan (Tables 4 and 5).

\section{Total lesions}

The total number of both bony and soft tissue metastatic lesions detected in the 50 patients calculated and represented in Tables 6 and 7. The overall sensitivity of DWIBS and STIR were $97.5 \%$ and $92.5 \%$, respectively. DWIBS was the most sensitive sequence with highest negative predictive values (Figs. 1 and 2).

On the other hand, T1WI was the least sensitive (85\%) with the lowest negative predictive value in comparison to other sequences.

The WB DWI was the most specific sequence in detecting metastatic bony and soft tissue lesions (specificity $100 \%$ with positive predictive value $=100 \%$ ), while its sensitivity was $87.5 \%$ with negative predictive value $=$ $66.6 \%$.

\section{Bony lesions}

DWIBS and STIR were the most sensitive with the highest negative predictive value. Both DWIBS and STIR detected more vertebral metastatic deposits $(100 \%$ and 97.8\%, respectively) than WB DWI and T1WI (Table 6).

Only WB-DWI had excellent lesion characterization due to the ability of measuring ADC value for the lesion (specificity and positive predictive value $100 \%$ ). However, WB-DWI missed 5 lesions, 3 vertebral, 1 pelvic, and 1 small lesion at the shoulder girdle. This is due to abdominal and respiratory movement and inadequate fat suppression.

T1WI, STIR, and even DWIBS could not characterize a suspected hip joint bony lesion either inflammatory or metastatic deposit. The case was finally interpreted as inflammatory lesion based on the ADC value applied on WB DWI (Fig. 3).

Table 4 Result of MR findings in 50 cases

\begin{tabular}{|c|c|c|c|c|}
\hline \multirow{2}{*}{$\begin{array}{l}\text { Cases } \\
\text { MRI sequence }\end{array}$} & \multicolumn{2}{|c|}{ +ve CASES 40} & \multicolumn{2}{|c|}{-ve CASES 10} \\
\hline & True +ve & False +ve & True -ve & False-ve \\
\hline $\mathrm{T1}$ & 34 & 3 & 7 & 6 \\
\hline ST & 37 & 2 & 8 & 3 \\
\hline WB-DW & 35 & 0 & 10 & 5 \\
\hline DWIBS & 39 & 1 & 9 & 1 \\
\hline
\end{tabular}

Table 5 Sensitivity, specificity, positive predictive value, and negative predictive value for total cases in all sequences

\begin{tabular}{lllll}
\hline Total & Sensitivity & Specificity & +ve predictive & -ve predictive \\
\hline T1 & $85 \%$ & $70 \%$ & $91.89 \%$ & $53.85 \%$ \\
ST & $92.5 \%$ & $80 \%$ & $94.87 \%$ & $72.72 \%$ \\
WB-DW & $87.5 \%$ & $100 \%$ & $100 \%$ & $66.67 \%$ \\
DWIBS & $97.5 \%$ & $90 \%$ & $97.5 \%$ & $90 \%$ \\
\hline
\end{tabular}

\section{Soft tissue lesions}

DWIBS and STIR were the most sensitive with high negative predictive values as both detected more soft tissue lesions (94.4\% for both) than T1WI and WB-DWI (Table 7).

DWIBS and WB-DWI detected one hepatic focal lesion more obviously, while STIR detected it in retrograde. However, WB-DWI missed 4 breast lesions due to inadequate fat suppression (Fig. 4).

DWIBS missed a small lung nodule and could not detect a small brain lesion as the lesion showed faint diffusion restriction on WB DWI and could not be detected with suppression signals on DWIBS. However, it showed breast lesions more obviously, even more than WB DWI and T1WI.

T1WI was the least sequences to detect hepatic and LN lesions, however detected breast lesions more than WB DWI.

\section{Discussion}

Metastatic breast cancer is defined when there is spread of the disease to involve other organs or other lymph nodes rather than the axillary lymph nodes [1].

Although metastatic lesions usually appear after several years from the primary lesions, sometimes detected at the same time when the primary lesion detected. Rarely, metastatic lesion can be detected before the primary lesions [2]. Breast cancer can be detected anywhere in body including lungs, regional lymph nodes, liver, and brain but mainly involving the bone [1, 2]. Management decision of oncology patients varies according to presence of metastatic lesion or not. Whole body imaging can detect distant metastatic lesions and can provide full information regarding the site, size, number, and shape. In addition, it can detect both bony and soft tissue

Table 6 Number and site distribution of metastatic bony lesions detected by MRI sequences

\begin{tabular}{lllll}
\hline Sequence site & T1 & ST & WB-DW & DWIBS \\
\hline Vertebra & 22 & 26 & 24 & 27 \\
Pelvic bone & 10 & 12 & 11 & 12 \\
Shoulder girdle & 6 & 6 & 5 & 6 \\
Total & $38(84.5 \%)$ & $44(97.8 \%)$ & $40(88.9 \%)$ & $45(100 \%)$ \\
Missed lesions & $7(15.5 \%)$ & $1(2.2 \%)$ & $5(11.1 \%)$ & $0(0 \%)$ \\
\hline
\end{tabular}


Table 7 Number and site distribution of metastatic soft tissue lesions detected by MRI sequences

\begin{tabular}{lllll}
\hline Sequence site & T1 & ST & WB-DW & DWIBS \\
\hline Liver & 2 & 3 & 5 & 5 \\
Lung & 9 & 9 & 9 & 8 \\
Breast & 10 & 12 & 8 & 12 \\
LNs & 7 & 9 & 9 & 9 \\
Brain & 1 & 1 & 1 & 0 \\
Total & $29(80.6 \%)$ & $34(94.4 \%)$ & $32(88.9 \%)$ & $34(94.4 \%)$ \\
Missed lesions & $7(19.4 \%)$ & $2(5.6 \%)$ & $4(11.1 \%)$ & $2(5.6 \%)$ \\
\hline
\end{tabular}

lesions. Bone scans and/or PET-CT scans are widely used for this purpose [3, 4]. MRI including DWI and DWIBS can also detect metastatic lesions; however, the relative availability of this technique and local experience should first be taken into account (Table 8), on the contrary to bone scan and PET-CT [9].

WB-DWI and DWIBS can be used to elicit metastases as the DWI is sensitive to the random (Brownian) motion of water molecules. In biologic tissue, the presence of impeding barriers (cell membranes, fibers, and macromolecules) interferes with the free displacement (diffusion) of water molecules [19]. Consequently, the

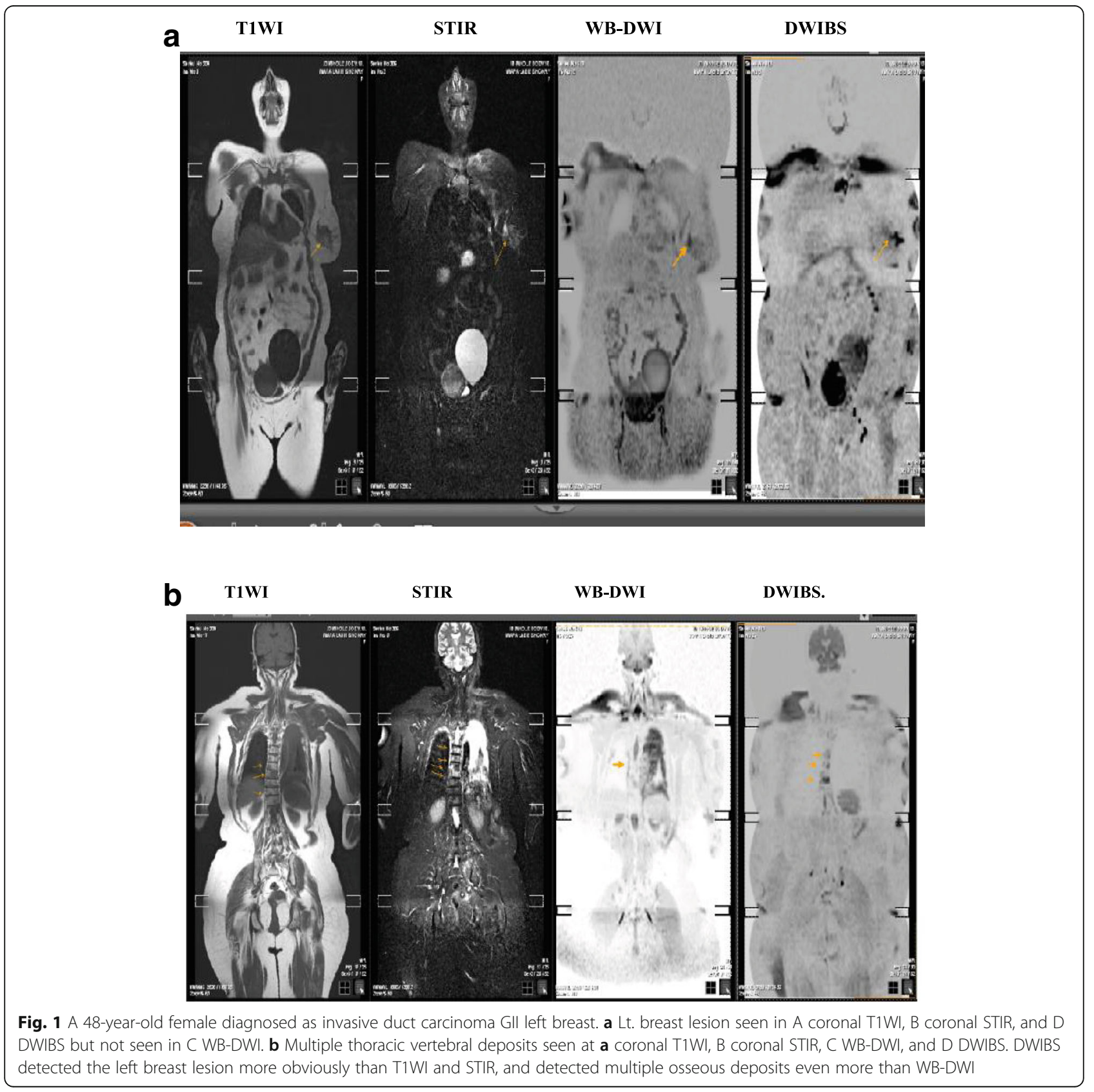




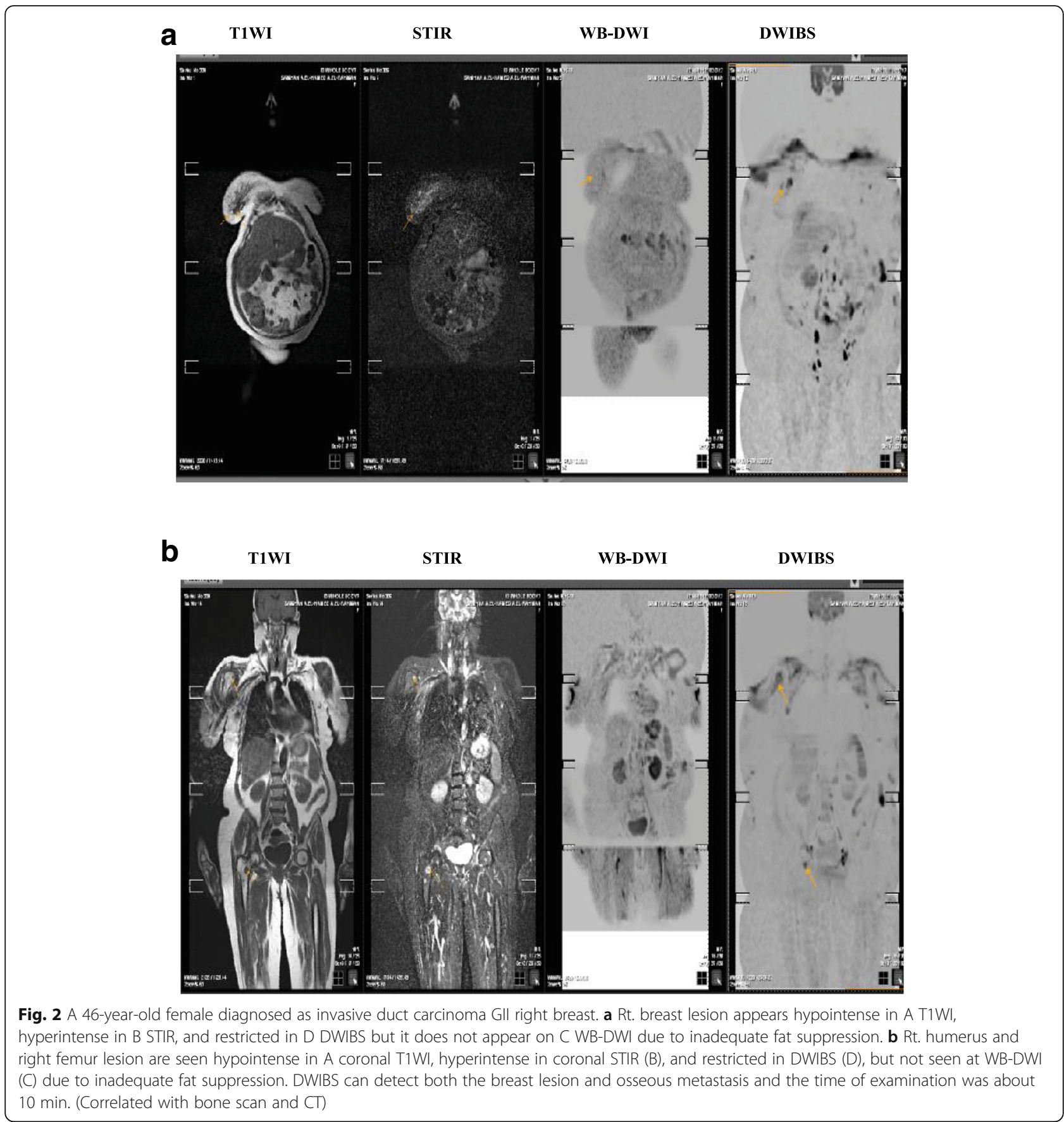

signal intensity in DWI depends on the separation and permeability of these impeding boundaries. The degree of restriction to water diffusion in biologic tissue is inversely correlated to the tissue cellularity and the integrity of cell membranes [20,21].

Tissues with a high cellular density show more restriction of the water molecules motion (e.g., tumor tissue). Based on this principle, the application of WB-DWI in evaluation of cancer patients is widely used and increasing, as the tumor tissue displays higher signal intensity (restricted diffusion) than the surrounding normal tissue [20,22].

Whole-body diffusion-weighted MRI (WB-DWI) and DWIBS are powerful sequences adjunct to anatomical whole-body MRI because it provides a functional assessment of disease, can quantify disease extent, does not require the administration of exogenous contrast medium and can be performed in reasonably short examination times $[3,20]$. Furthermore, WB-DWI can improve the reading and test performance of anatomical 


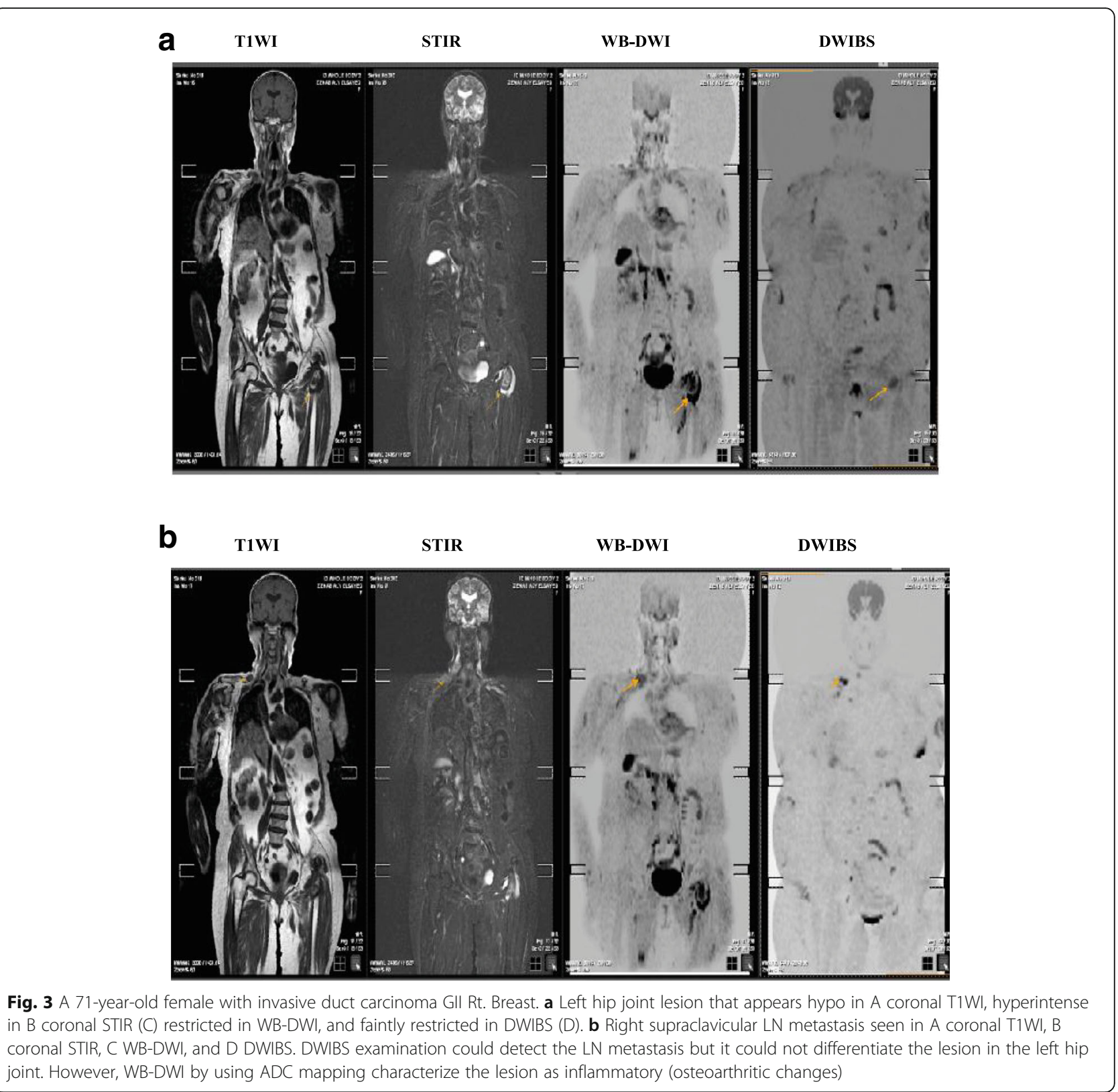

whole-body MR examinations because areas of increased cellularity are depicted as regions of high signalintensity, therefore allowing an 'at-a-glance' assessment of disease and distribution [11,23].

Initial studies describing WB-DWI imaging were focusing on detection of the metastatic bony lesions especially in patients having malignancies known to have high incidence of metastatic spread to the skeletal system [24]. However, the subsequent studies and application of DWIBS show the additional value of this sequence in comparison to WB-MR imaging without DWI $[25,26]$.

In the current study, it was obviously noted that DWIBS takes short time on patient examination (about
10 to $15 \mathrm{~min}$ ) while WBDWI with $2 b$ values takes about $45 \mathrm{~min}$, and both T1WI and STIR takes about $30 \mathrm{~min}$ each. This denotes that DWIBS is easier for the patient and allowing saving money and time and this goes with the study of Takahara $\mathrm{T}$ [27].

In this study, 50 female patients (their ages ranged between 31 to 76 years and mean age 49 years) were pathologically proven primary breast malignancy cases. All the 50 patients underwent T1WI and STIR sequences for anatomical correlation and adequate assessment. This is similar to the study done by Abdel Wahab et al. [28].

The resulting DWIBS images were displayed by using black and white inverse gray scales. This goes with the 


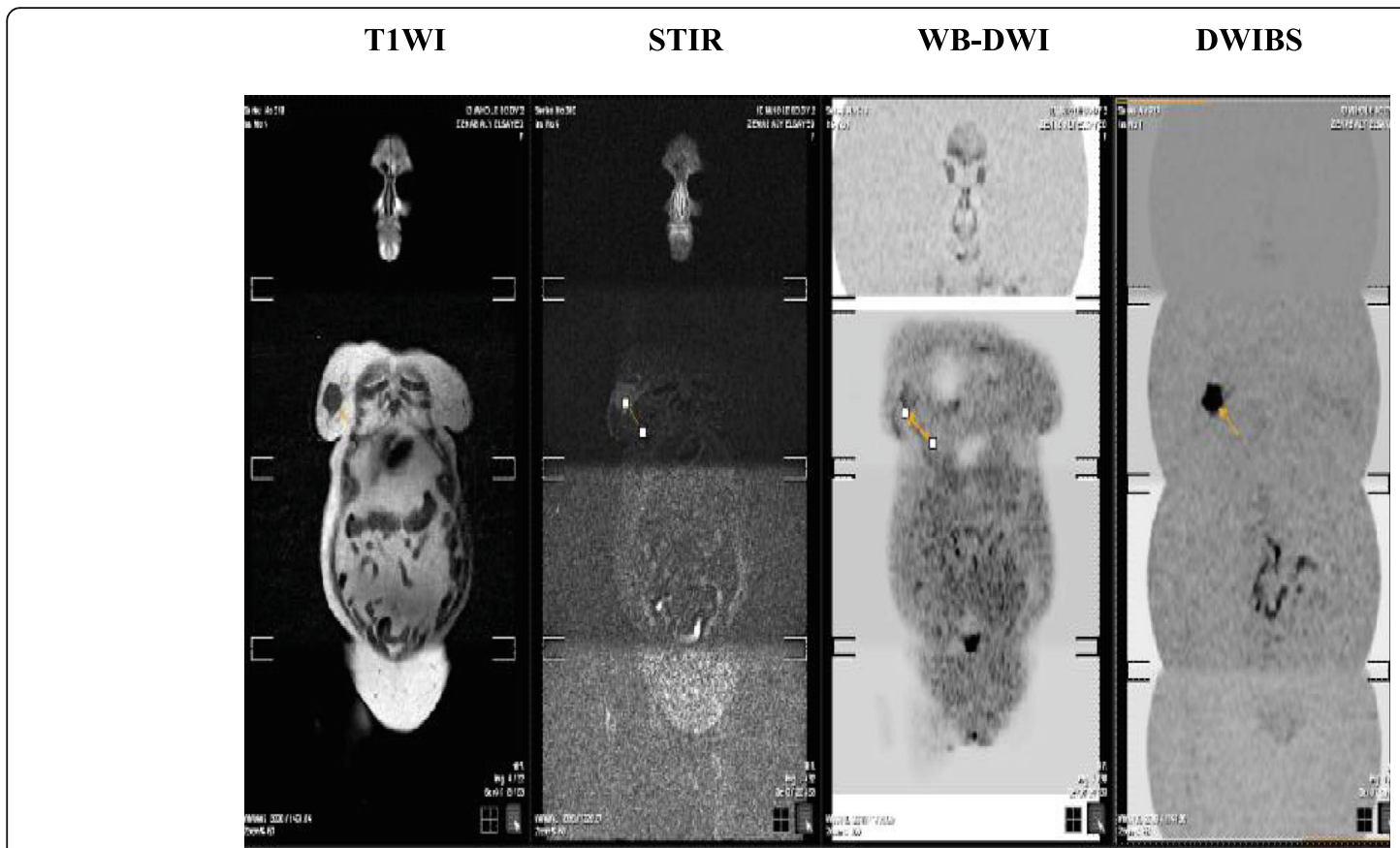

Fig. 4 A 31 year old female diagnosed as invasive duct carcinoma GII Rt. Breast. Rt. breast lesion that is seen in a coronal T1WI, b coronal STIR, and $\mathbf{d}$ DWIBS but not seen in $\mathbf{c}$ WB-DWI due to inadequate fat suppression. DWIBS examination could detect the breast lesion and denote absence of osseous and soft tissue metastasis, and time of scan was only 15 min

parameters used in the study by Sushil G. et al. [29] The detected metastatic lesions (in the 50 patients) were classified into two main groups, metastatic soft tissue lesion and metastatic bony lesions detected by computed tomography and bone scan as a standard for comparison and correlation with the findings of whole body diffusion MRI. This goes with the method of analysis done in the study of Abdel Wahab et al. [28].

In this study, WB-DWI MRI detected almost all metastatic soft tissue extra osseous lesions and almost all metastatic bony lesions. Its sensitivity in detection of metastatic lesions was $87.5 \%$, while its specificity was $100 \%$ with positive predictive value $=100 \%$ (the

Table 8 The relative availability of DWIBS MRI on the contrary to bone scan and PET-CT

\begin{tabular}{llll}
\hline Criteria & Bone scan & PET Scan & DWIBS MRI \\
\hline Availability & Less & Lesser & More \\
Prior preparation & Needed & Needed & Unnecessary \\
Scan time & More & More & Less \\
Radiation exposure & Yes & Yes & No \\
Repeatability & Limited & Limited & Unlimited \\
Usage in pregnant patients & No & No & Unlimited \\
Usage in pediatric patients & Limited & Limited & Unlimited \\
Cost of study & More & More & Less \\
\hline
\end{tabular}

most specific MR sequence). On the other hand, the sensitivity and negative predictive value of both STIR and DWIBs were higher (DWIBS was the most sensitive sequence $(97.5 \%)$ ), and this is nearly similar to the results reported by Abdel Wahab et al. [28].

In the current study, DWIBS was $100 \%$ sensitive in detection of metastatic bony lesions and had positive predictive value $=100 \%$. Similar results were reported by Gandage SG. et al. [30] and Kachewar SG [31]. While in detection of metastatic extra-osseous lesions, its sensitivity was $94.4 \%$ with positive predictive value $=97.5 \%$.

In the current study, WB-DWI detected most of metastatic bony lesions. The missed lesions were three in lumber vertebrae, one at the shoulder girdle, and one at the pelvic bones, mostly due to intestinal and respiratory movement as have other studies reported [23, 32, 33].

In this study, a suspicious pelvic bony lesion could not be differentiated by DWIBS, T1WI, or STIR sequences whether being malignant or inflammatory. On the other hand, on WB-DWI with ADC mapping, it was certified to be inflammatory; so it was concluded that WB-DWI is more useful in lesion characterization which goes with the studies done by Cheng L.I. et al. [34] and Sommer G. et al. [35]. Sun et al. [36] have reported that DWIBS coupled with $\mathrm{ADC}$ analysis at $3 \mathrm{~T}$ is effective in detection of bone metastases. 
One of the major advantages of the DWIBS sequence is that it can detect and assess the extra-osseous lesions $[37,38]$. In this study, almost all metastatic soft tissue lesions were detected by DWIBS including the liver, lung, breast, and lymph nodes with overall sensitivity 94.4\%. However, a small lung nodule and a small brain lesion were missed in DWIBS. So, whole body MRI (T1 and STIR) was complementary to detect these lesions. The missed lung lesion could be attributed to signal loss and artifacts due to severe tissue motion as reported by Daniel P. et al .[12] and Sakurada A et al. [39].

In current study, WB-DWI was able to detect almost all extra osseous lesions only missed four breast lesions with sensitivity $88.9 \%$. This is mostly due to inadequate fat suppression, as these lesions were obviously shown at the DWIBS sequence as a result of the adequate fat suppression. Similar findings were reported by Takahara $\mathrm{T}$ [27]. and Koh DM. et al. [40].

Also, both WB-DWI and DWIBs obviously show small hepatic focal lesions which are noted in retrograde in other MRI sequences. So, both can be applied for extraskeletal tumor detection and characterization. Similar response was achieved in a study done by Vilanova JC. et al. [37] and also goes with the study of Tomizawa M. et al. [38].

Also, Cheng L.I., et al .[34] had studied the ability of DWIBS in detection of metastatic deposits in various location concerning bone, LN, and solid organs and concluded a different result than in this study, as the ability of conventional MRI sequences to detect osteoblastic metastasis, mediastinal LNs, lung, and brain metastases were better than WB-DWI in their study. New studies reported that DWIBS/STIR sequences are effective modality for the pre-therapeutic staging and management. DWIBS has a promising imaging tool in the evaluation of patients with malignancies [41, 42].

This study concluded that whole body DWIBS can accurately detect both bony and extra osseous soft tissue metastatic lesions, as DWIBS detected almost all metastatic lesions detected by other modalities (CT and bone scan) in all patients included in the study. High degree of agreement existed between DWIBS and STIR than between DWIBS and other conventional MRI sequences. However, the number of lesions in each case depicted in DWIBS was higher than those depicted in other sequences, while the conventional MRI sequences localized these lesions more accurately.

\section{Limitations of the current study}

There were two main limitations of this study; the first one was the small sample size and the other limitation was that biopsy could not be taken from all metastatic lesions; however, all contributed patients had pathologically proven breast cancer.

\section{Conclusion}

DWIBS MRI sequence is an effective method for detection of solid organ, bone, and lymph node metastasis but not specific for characterization of lesions. It has excellent diagnostic accuracy in detection of distant metastatic lesions and represents a promising tool for tumor surveillance and metastatic workup of the oncology patients. In addition, there is no hazards of ionizing radiation or contrast media administration and also has better spatial resolution. The relative availability of this technique and local experience should first be taken in consideration.

\section{Abbreviations}

DWIBS: Diffusion-weighted whole body imaging with background body signal suppression; WB-DWl: Whole body diffusion-weighted image; MRI: Magnetic resonance imaging; DWl: Diffusion-weighted image; MDCT: Multi-detector computed tomography; ADC: Apparent diffusion coefficient; SPSS: Statistical Package for Social Science

\section{Acknowledgements}

Not applicable

\section{Authors' contributions}

Guarantor of integrity of the entire study: W.H.K, M. G. E., and K.F. Study concepts and design: W.H.K, M. G. E., and T.A. Literature research: W.H.K, A.S., M. G. E., and K.F. Clinical studies: W.H.K, A.S., M. G. E., and T.A. Experimental studies/data analysis: W.H.K, A.S., M. G. E., and K.F. Statistical analysis: W.H.K, A.S., M. G. E., and K.F. Manuscript preparation: W.H.K, M. G. E., and T.A. Manuscript editing: W.H.K, A.S. M. G. E., and K.F. All authors read and approved the final manuscript.

Funding

Not applicable.

Availability of data and materials

The datasets used and/or analyzed during the current study available from the corresponding author on reasonable request.

\section{Declaration}

Ethics approval and consent to participate

This study had approval from the Institutional Review Board of King Faisal Specialist Hospital and Research Center, Jeddah, KSA. Ethics committee's reference number is not available. Written informed consent was obtained from all patients.

Consent for publication

All patients included in this research gave written informed consent to publish the data contained within this study. If the patient was less than 16 years old, deceased, or unconscious when consent for publication was requested, written informed consent for the publication of this data was given by their parent or legal guardian.

Competing interests

All authors declare that they have no competing interests.

Author details

${ }^{1}$ Radiology Department, Minia University, Minia, Egypt. ${ }^{2}$ Radiology Department, Ain-Shams University, Cairo, Egypt. ${ }^{3}$ Medical Oncology Department, Mansoura University, Mansoura, Egypt. ${ }^{4}$ Radiology Department, Mansoura University, El Gomhorya St, Mansoura 35111, Egypt. ${ }^{5}$ Faculty of Medicine, Department of Diagnostic and Intervention Radiology, Mansoura University, El Gomhorya St, Mansoura 35111, Egypt. 
Received: 29 December 2020 Accepted: 24 February 2021 Published online: 10 March 2021

\section{References}

1. Cardoso F, Costa A, Senkus E et al (2017) 3rd ESO-ESMO International Consensus Guidelines for Advanced Breast Cancer (ABC 3). Ann Oncol 28(12):3111

2. Kennecke $H$, Yerushalmi R, Woods $R$ et al (2010) Metastatic behavior of breast cancer subtypes. J Clin Oncol 28(20):3271-3277

3. Fischer MA, Nanz D, Hany T et al (2011) Diagnostic accuracy of whole-body MRI/DWI image fusion for detection of malignant tumours: a comparison with PET/CT. Eur Radiol 21(2):246-255

4. Lee SC, Jain PA, Jethwa SC et al (2014) Radiologist's role in breast cancer staging: providing key information for clinicians. Radiographics 34(2):330342

5. Gu J, Kwong YL, Chan T et al (2010) Comparison of DWIBS and 18F-FDG PET/CT in newly diagnosed lymphoma. Proc Intl Soc Mag Reson Med 18:90

6. Chan SC, Wang HM, Yen TC et al (2011) 18F-FDGPET/CT and 3.0-T wholebody MRI for the detection of distant metastases and second primary tumors in patients with untreated oropharyngeal/hypopharyngeal carcinoma: a comparative study. Eur J Nucl Med Mol Imaging 38(9):16071619

7. Wu LM, Gu HY, Zheng J et al (2011) Diagnostic value of whole-body magnetic resonance imaging for bone metastases: a systematic review and meta-analysis. J Magn Reson Imaging 34(1):128-135

8. Gutzeit A, Doert A, Froehlich JM et al (2010) Comparison of diffusionweighted whole body MRI and skeletal scintigraphy for the detection of bone metastases in patients with prostate or breast carcinoma. Skeletal Radiol 39(4):333-343

9. Takahara T, Imai Y, Yamashita T et al (2004) Diffusion weighted whole body imaging with background body signal suppression (DWIBS): technical improvement by using free breathing, STIR and high resolution 3D display. Radiat Med 22:275-282

10. Padhani A, Koh D (2011) Whole-body diffusion-weighted MR imaging in cancer: cur-rent status and research directions. Radiology 261(3):700-718

11. Kwee TC, Takahara T, Ochiai R et al (2008) Diffusion-weighted whole-body imaging with background body signal suppression (DWIBS): features and potential applications in oncology. Eur Radiol. 18:1937-1952. https://doi. org/10.1007/s00330-008-0968-z

12. Noija DP, Boerhouta EJ, Pieters IC et al (2014) Whole-body-MR imaging including DWIBS in the work-up of patients with head and neck squamous cell carcinoma: A feasibility study. Eur J Radiol 83:1144-1151

13. Kachewar SG, Kulkarni DS. And Sankay S B. (2011): DWIBS imaging: monitoring MRI to monitor metastases. J Clin Diagn Res; 57: 1410-1412.

14. Plathow C, Walz M, Lichy MP et al (2008) Cost considerations for wholebody MRI and PET/CT as part of oncologic staging. Radiologe 48(4):384-396

15. Mürtz P, Krautmacher C, Träber F et al (2007) Diffusion-weighted wholebody MR imaging with background body signal suppression: a feasibility study at 3.0 T. Eur Radiol 17(12):3031-3037

16. Eiber M, Holzapfel K, Ganter C et al (2011) Whole-body MRI including diffusion-weighted imaging (DWI) for patients with recurring prostate cancer: technical feasibility and assessment of lesion conspicuity in DWI. J Magn Reson Imaging 33(5):1160-1170

17. Lin C, Luciani A, Itti E et al (2010) Whole-body diffusion-weighted magnetic resonance imaging with apparent diffusion coeffi cient mapping for staging patients with diffuse large B-cell lymphoma. Eur Radiol 20(8):2027-2038

18. Schmidt GP, Reiser MF, Baur-Melnyk A (2009) Whole-body MRI for the staging and follow-up of patients with metastasis. Eur J Radiol 70:393-400

19. Padhani AR, Lecouvet FE, Tunariu N et al (2017) Metastasis reporting and data system for prostate cancer: practical guidelines for acquisition, interpretation, and reporting of whole-body magnetic resonance imagingbased evaluations of multiorgan involvement in advanced prostate cancer Eur Urol. 71(1):81-92

20. Kosmin M, Makris A, Joshi PV et al (2017) The addition of whole-body magnetic resonance imaging to body computerized tomography alters treatment decisions in patients with metastatic breast cancer. Eur J Cancer. 77:109-116

21. Padhani AR, Koh D-M, Collins DJ (2011) Whole-Body Diffusion-weighted MR Imaging in Cancer: Current Status and Research Directions. Radiology 261:3
22. Padhani AR and Gogbashian A. (2011): Bony metastases: assessing response to therapy with whole-body diffusion MRI. Cancer Imaging:11 Spec No A: S129-S145.

23. Godinho M, Paiva F, CostaF (2018) Whole-body magnetic resonance imaging for the assessment of metastatic breast cancer. Cancer Manage Res 10:6743-6756

24. Lecouvet FE (2016) Whole-Body MR Imaging: musculoskeletal applications. Radiology 279(2):345-365

25. Nakanishi K, Kobayashi M, Takahashi S et al (2005) Whole body MRI for detecting metastatic bone tumor: Comparison with bone scintigram. Magn Reson Med Sci 4:11-17

26. Nava D, Cesar H, Luisi FA et al (2011) Whole-body magnetic resonance imaging for staging and follow-up of pediatric patients with Hodgkin's lymphoma: Comparison of different sequences. Radiol Bras 44(1):29-34

27. Takahara T (2005) DWIBS:Diffusion - weighted whole-body imagining with background body signal suppression. Medicamundi 49:3-11

28. Abdel wahab N.M, Awadlalah M.Y and Bassam A.M. (2013) Role Of whole body diffusion weighted MRI in assessment of neoplastic lesion. Med J Cairo Univ, 81, No 2 March: 213-220.

29. Kashewar SG, Kulkarni DS, Sankaye SB (2011) DWIBS Imaging: Modifying MR to Monitor Metastases. J Clin Diagn Res (Suppl-2) 5(7):1410-1412

30. Gandage SG, Kachewar SG, Aironi VD et al (2012) A comparative study of whole body DWIBS MRI versus bone scan for evaluating skeletal metastases. Aust Med J 5(12):619-622

31. Kachewar SG (2011) Using DWIBS MRI technique as an alternative to bone scan or PET scan for whole-body imaging in oncology patients. Acta Radiol $52: 788$

32. Ghanem N, Lohrmann C, Engelhardt M et al (2006) Whole-body MRI in the detection of bone marrow infiltration in patients with plasma cell neoplasms in comparison to the radiological skeletal survey. Eur. Radiol. 16: 1005-1014

33. ZugnilD F, Ruju F, Pricolo $P$ et al (2018) The added value of whole-body magnetic resonance imaging in the management of patients with advanced breast cancer. PLoS One 13(10):e0205251. https://doi.org/10.1371/ journal.pone.0205251 October 12

34. Cheng LI, Zhen-Sheng LIU, Xian-Mao DU et al (2009) Clinical value of whole-body magnetic resonance diffusion weighted imaging on detection of malignant metastases. Chin Med Sci J 24(2):112-116

35. Sommer G, Klarhöfer M, Lenz C et al (2011) Signal characteristics of focal bone marrow lesions in patients with multiple myeloma using whole body T1w-TSE, T2w-STIR and diffusion-weighted imaging with background suppression. Eur Radiol 21(4):857-862

36. Sun W, Li M, Yifeng G et al (2020) Diagnostic value of whole-body DWI with background body suppression plus calculation of apparent diffusion coefficient at 3 T versus 18F-FDG PET/CT for detection of bone metastases. AJR 214:446-454

37. Vilanova JC, Barcelo J (2008) Diffusion-weighted whole-body MR screening. Eur J Radiol 67:440-447

38. Tomizawa M, Shinozaki F, Fugo K et al (2017) Diagnostic accuracy of diffusion-weighted whole-body imaging with background body signal suppression/T2-weighted image fusion for the detection of abdominal solid cancer. Exp Ther Med 13:3509-3515

39. Sakurada A, Takahara T, Kwee TC et al (2009) Diagnostic performance of diffusion weighted magnetic resonance imaging in esophageal cancer. Eur. Radiol. 19:1461-1469

40. Koh DM, Blackledge M, Padhani AR et al (2012) Whole-body diffusion weighted MRI: tips, tricks, and pitfalls. AJR Am J Roentgenol. 199(2):252-262

41. Hong G-S, Chae EJ, Ryu J-S et al (2021) Assessment of naive indolent lymphoma using whole-body diffusion-weighted imaging and T2weighted MRI: results of a prospective study in 30 patients. Cancer Imaging 21(5):371-376

42. Rezk M, Nasr I, Ali I et al (2019) Comparative Study between 18F FDG-PET/ CT and Whole Body MRI DWIBS in Assessment of Recurrent Breast Cancer (Prospective, Comparative, Cross-sectional Study Design). Indian J Nucl Med. 34(1):1-9

\section{Publisher's Note}

Springer Nature remains neutral with regard to jurisdictional claims in published maps and institutional affiliations. 